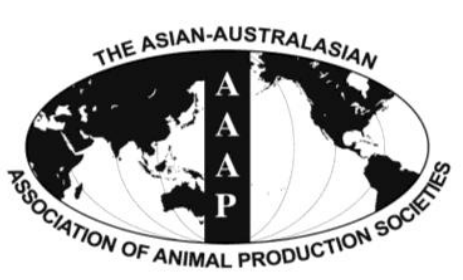

Open Access

Asian Australas. J. Anim. Sci.

Vol. 27, No. 1 : 93-100 January 2014

http://dx.doi.org/10.5713/ajas.2013.13411

www.ajas.info

pISSN 1011-2367 elSSN 1976-5517

\title{
Comparison of Single and Blend Acidifiers as Alternative to Antibiotics on Growth Performance, Fecal Microflora, and Humoral Immunity in Weaned Piglets
}

\author{
S. T. Ahmed, J. A. Hwang, J. Hoon, H. S. Mun, and C. J. Yang* \\ Department of Animal Science and Technology, Sunchon National University, Suncheon, Jeonnam 540-742, Korea
}

\begin{abstract}
The banning of the use of antibiotics as feed additive has accelerated investigations of alternative feed additives in animal production. This experiment investigated the effect of pure citric acid or acidifier blend supplementation as substitute for antibiotic growth promoters on growth performance, fecal microbial count, and humoral immunity in weaned piglets challenged with Salmonella enterica serover Typhimurium and Escherichia coli KCTC 2571. A total of 60 newly weaned piglets (crossbred, 28-d-old; average $8 \mathrm{~kg}$ initial weight) were randomly assigned to four dietary treatments in a completely randomized design. Dietary treatments included NC (negative control; basal diet), PC (positive control; basal diet $+0.002 \%$ apramycin), T1 (basal diet $+0.5 \%$ pure citric acid), and T2 (basal diet $+0.4 \%$ acidifier blend). All piglets were orally challenged with $5 \mathrm{~mL}$ of culture fluid containing $2.3 \times 10^{8} \mathrm{cfu} / \mathrm{mL}$ of E. coli KCTC 2571 and $5.9 \times 10^{8} \mathrm{cfu} / \mathrm{mL}$ of S. typhimurium at the beginning of the experiment. The PC group showed the highest ADG and ADFI, whereas gain:feed was improved in the PC and T1 group $(\mathrm{p}<0.05)$. All dietary treatments showed significant reduction in fecal counts of Salmonella and E. coli, compared to NC (p<0.05), with PC being better than T1 and T2. Significant elevation in fecal Lactobacillus spp. counts was shown by treatments with T1, T2, and PC, whereas Bacillus spp. counts were increased by treatment with $\mathrm{T} 1$ and $\mathrm{T} 2$ compared to $\mathrm{NC}$ and PC diet $(\mathrm{p}<0.05)$. Serum IgG concentration was increased by $\mathrm{T} 1 \operatorname{diet}(\mathrm{p}<0.05)$, whereas $\operatorname{IgM}$ and $\operatorname{IgA}$ were not significantly affected by any of the dietary treatments $(p>0.05)$. From these above results, it can be concluded that, as alternatives to antibiotics dietary acidification with pure citric acid or acidifiers blend did not fully ameliorate the negative effects of microbial challenges in respect of growth performance and microbial environment, however improved immunity suggested further research with different dose levels. (Key Words: Citric Acid, Acidifier Blend, Growth Performance, Microorganism, Immunity, Challenged Piglets)
\end{abstract}

\section{INTRODUCTION}

It is generally accepted that the species of microorganisms in the intestinal tract and their ratio have a major impact on animal health (Deng et al., 2007a). Intestinal microorganisms compete with each other for limited source of nutrients and adhesion sites in the intestinal tract both of which are necessary for their growth. Several studies have confirmed the influence of dietary composition and nutrient content on the intestinal microbial ecosystem (Bauer et al., 2001; Li et al., 2008). In case of

\footnotetext{
* Corresponding Author: Chul-Ju Yang. Tel: +82-61-750-3235, Fax: +82-61-750-3239, E-mail: yangcj@ scnu.kr

Submitted Jul. 11, 2013; Accepted Sept. 21, 2013; Revised Oct. 14, 2013
}

early weaning, sudden dietary changes due to transition from readily digestible sow milk to an unfamiliar starter diet with high protein content and high acid-binding capacity (Eidelsburger, 1998) combined with the inability of piglets to secrete sufficient quantities of hydrochloric acid $(\mathrm{HCl})$ in their immature gastrointestinal tracts (GIT) leads to digestive disturbance (Barnett et al., 1989; Wu et al., 2012) and invasion of acid-intolerant bacteria, including $E$. coli and Salmonella (Smith and Jones, 1963; Marinho et al., 2007). The immune system, especially acquired immunity, plays an important role in protecting piglets against pathogenic infection (Li et al., 2007). However, acquired immunity is underdeveloped at the age of 3 to 4 weeks because of ending lactation immunity (Deng et al., 2007b). This immunological challenge together with microbial

Copyright (? 2014 by Asian-Australasian Journal of Animal Sciences This is an open-access article distributed under the terms of the Creative Commons Attribution Non-Commercial License (http://creativecommons.org/licenses/by-nc/3.0/), which permits unrestricted non-commercial use, distribution, and reproduction in any medium, provided the original work is properly cited. 
infection results in depressed feed intake, poor growth, post-weaning diarrhea syndrome (PWDS) and consequent increased economic loss for pig producers (Kyriakis, 1989; Guo et al., 2008). Traditionally, antibiotics were successfully applied to overcome weaning stresses and to improve performance (Chopra et al., 1964). However, drug residues in edible meat products and their potential contribution to the emergence of antibiotic-resistance bacteria threaten human health (Fuller, 1992) and there is a consumer outcry to eliminate non-therapeutic antibiotics use in animal agriculture (Doyle, 2001).

Dietary acidifiers (organic and inorganic acids) have been broadly applied worldwide in diets of animals in order to replace antibiotic growth promoters, because of their potential to reduce the GIT-pH, which improves nutrient digestion and protects the GIT from pathogenic bacteria invasion and proliferation (Kil et al., 2011). The US Food and Drug Administration classify many organic and inorganic acids as GRAS (Generally recognized as safe) substances (AACC, 2000). Experiments on pigs have shown that supplementation of weanling pig diets with pure organic acid, a mixture of organic acids and/or their salts improves growth performance (Partanen and Morz, 1999; Tsiloyiannis et al., 2001) as well as reduces the number of pathogenic bacteria in the GIT (Cole et al., 1968). Dietary supplementation of citric acid was found to have improved growth performance and reduced GIT-pH in weanling pigs (Radcliffe et al., 1998). In a meta-analysis of porcine diarrhea to dietary acidifiers, Tsiloyiannis et al. (2001) indicated that citric, formic, fumaric, lactic and propionic acid improved the ADG, feed efficiency (gain:feed ratio), reduced $E$. coli infection and incidence of diarrhea in postweaning piglets. It is established through many scientific studies that dietary organic acids create an acidic condition in the GIT by lowering $\mathrm{pH}$ which has bactericidal or bacteriostatic effects (Hansen et al., 2007) on pathogenic microbes. Reduction in pathogen concentration resulted in reduced toxic bacterial metabolites and competition for nutrients with the host, thus improving weight gain of the host. However, organic acid is too expensive to utilize in animal feed (Kil et al., 2006). On the contrary, inorganic acids are cheaper and reported to exert a similar effect on growth performance as organic acidifiers (Schoenherr, 1994). Furthermore, blending of various organic and inorganic acidifiers has gained attention because of their synergistic action to improve health and performance of weanling pigs (Kil et al., 2011). Many findings have shown that dietary acidifiers provide a prophylactic measure similar to antibiotics (Sciopioni et al., 1978; Mathew et al., 1991). Accordingly, acidifiers reduce harmful microorganisms and promote beneficial microbial growth in the GIT (Mathew et al., 1991) while, antibiotics are designed to inhibit most microbial growth including beneficial ones (Cromwell, 1991). It has also been reported that the nutritive effects of organic acids are most pronounced in weaning pigs (Gabert and Sauer, 1994; Roth and Kirchgessner, 1998). However, the effects of acidifiers were often found to vary on the performance of animals and consequently more intense studies are essential to elucidate their specific effects. Therefore, this study investigated the effects of pure citric acid and acidifier blend supplementation as an alternative to antibiotics on growth performance, fecal microbial population, and immunity of weaning pigs orally challenged with Salmonella enterica serover Typhimurium and Escherichia coli KCTC 2571.

\section{MATERIALS AND METHODS}

The present research was carried out in accordance with the guidelines for the care and use of animals in research (Korean Ministry for Food, Agriculture, Forestry and Fisheries, 2008). All experimental procedures used in this study were approved by the Animal Care and Use Committee of Sunchon National University.

\section{Animal and experimental design}

The experiment was carried out using a completely randomized design where sixty 28 -d-old weaned piglets were randomly assigned to four dietary treatments, each consisting of 15 piglets (three replicate pens of 5 pigs/pen). All piglets were derived from sows (Landrace $\times$ Yorkshire) mated with Duroc boars, and were living in an E. coli and Salmonella-free commercial farm under same housing conditions. The piglets were selected with an equal sex ratio of 30 males and 30 females considering an average body weight of $8 \mathrm{~kg}$. Experimental diets included: NC (negative control), basal diet without additive supplementation; PC (positive control), basal diet supplemented with $0.002 \%$ apramycin; T1, basal diet with $0.5 \%$ citric acid (citric acid $100 \%$ ); and $\mathrm{T} 2$, basal diet with $0.4 \%$ acidifier blend $(17.2 \%$ formic acid, $4.1 \%$ propionic acid, $10.2 \%$ lactic acid, 9.5\% phosphoric acid, $\mathrm{SiO}_{2} 34.0 \%$ ). A commercial pellet pig starter diet was used as a basal diet, formulated to meet or exceed the nutrient requirements of weaned pigs as recommended by the National Research Council (NRC, 1998). Molasses was added at $4.3 \%$ level to help in the manufacture of pellets. The ingredients and chemical compositions of the experimental diets are presented in Table 1. The pellet diet was ground using a milling machine to reduce the particle size. The apramycin and organic acids were added in the feed of each experimental diet by replacing equal amount of basal diet. It was considered that the small amounts of the acids did not affect the energy value of the diet, compared to the basal diet. 
Table 1. Ingredients and chemical composition of basal diets (starter)

\begin{tabular}{|c|c|}
\hline Item & \\
\hline \multicolumn{2}{|l|}{ Ingredients (\%, as-fed basis) } \\
\hline Yellow corn & 45.15 \\
\hline Wheat & 23.00 \\
\hline Wheat bran & 4.00 \\
\hline Soybean meal & 18.00 \\
\hline Limestone & 0.98 \\
\hline Calcium phosphate & 1.10 \\
\hline Salt & 0.25 \\
\hline Vitamin and mineral premix ${ }^{1}$ & 0.55 \\
\hline Animal fat & 2.50 \\
\hline Molasses & 4.30 \\
\hline L-lysine.HCL (78\%) & 0.17 \\
\hline \multicolumn{2}{|l|}{ Chemical composition (as fed basis) } \\
\hline $\mathrm{ME}(\mathrm{kcal} / \mathrm{kg})$ & 3,265 \\
\hline Crude protein $(\%)$ & 18.00 \\
\hline $\mathrm{Ca}(\%)$ & 0.70 \\
\hline Available phosphorus (\%) & 0.55 \\
\hline Lysine (\%) & 0.95 \\
\hline Methionine $(\%)$ & 0.30 \\
\hline \multicolumn{2}{|c|}{$\begin{array}{l}{ }^{1} \text { Vitamin mix provided the following nutrients per kg of premix: vitamin } \\
\text { A } 6,000 \mathrm{IU} \text {; vitamin } \mathrm{D}_{3} 800 \mathrm{IU} \text {; vitamin } \mathrm{E} 20 \mathrm{IU} \text {; vitamin } \mathrm{K}_{3} 2 \mathrm{mg} \text {; } \\
\text { thiamin } 2 \mathrm{mg} \text {; riboflavin } 4 \mathrm{mg} \text {; vitamin } \mathrm{B}_{6} 2 \mathrm{mg} \text {; vitamin } \mathrm{B}_{12} 1 \mathrm{mg} \text {; } \\
\text { pantothenicacid } 11 \mathrm{mg} \text {; niacin } 10 \mathrm{mg} \text {; biotin } 0.02 \mathrm{mg} \text {; Cu (copper } \\
\text { sulfate) } 21 \mathrm{mg} \text {; Fe (ferrous sulfate) } 100 \mathrm{mg} \text {; } \mathrm{Zn} \text { (zinc sulfate) } 60 \mathrm{mg} \text {; Mn } \\
\text { (manganese sulfate) } 90 \mathrm{mg} \text {; (calcium iodate) } 1.0 \mathrm{mg} \text {; Co (cobalt nitrate) } \\
0.3 \mathrm{mg} \text {; Se (sodium selenite) } 0.3 \mathrm{mg} \text {. }\end{array}$} \\
\hline
\end{tabular}

All piglets were orally challenged with $5 \mathrm{~mL}$ of culture fluid containing $2.3 \times 10^{8} \mathrm{cfu} / \mathrm{mL}$ of $E$. coli KCTC 2571 and $5.9 \times 10^{8} \mathrm{cfu} / \mathrm{mL}$ of $S$. typhimurium at the back of the oral cavity using a micropipette tip at the beginning of the experiment. The bacterial solution was slowly dribbled into each piglet's throat in order to trigger the swallowing reflex and minimize the passage of inoculants into the lungs. The goal of the challenge was to use it as a model of postweaning lag phage which is manifested by imbalance microbiota in the intestine and ultimate poor growth performance and immunity. All piglets were housed in an environmentally controlled nursery facility with hardplastic slatted floor in 12 adjacent pens $(1.8 \times 1.8 \mathrm{~m})$ to prevent possible cross-contamination. Each pen was equipped with a one-sided self-feeder and a nipple drinker to allow the pig ad-libitum access to feed and water throughout the experimental period. The target room temperature and humidity were $25^{\circ} \mathrm{C}$ and $60 \%$, respectively.

\section{Measurements and analyses}

Individual piglets' body weight was measured at 0,14 , and 28 day of the experiment. Feed consumption per pen was recorded during the same period and the ADG, ADFI, and gain:feed were calculated. The ADG and ADFI were calculated by dividing total pen weight gain and total pen feed consumption by the number of animal days. The gain:feed for each pen was calculated by dividing the ADG by the ADFI.

On d 1 of the trial, two piglets were identified from each pen by a double ear-tag for subsequent microbial and immunological analysis. On d 7, 14, 21, and 28 of the experiment fresh fecal samples were collected directly from the rectum of these piglets in sterile polyethylene bags, via manual stimulation of the internal and external anal sphincters, in order to avoid any additional contamination of the samples. Samples were then serially diluted 10 -fold in sterile saline $(0.9 \%)$ and inoculated onto agar plates. The following were used as incubation media: SalmonellaShigella agar (SS) was used for Salmonella, MacConkey agar (MAC) was used for E. coli, Mann, Rogosa and Sharpe agar (MRS) was used for Lactobacillus, and Mannitol Egg Yolk Polymyxin agar (MYP) was used for Bacillus isolation. Microbial plates were inoculated with three dilutions, each in duplicate. Agar plates were then incubated anaerobically at $37^{\circ} \mathrm{C}$ for $48 \mathrm{~h}$, after which microbial colonies were immediately counted. Microflora enumerations were expressed as $\log _{10} \mathrm{cfu} / \mathrm{mL}$.

For immunological analysis, blood samples $(10 \mathrm{~mL})$ were collected directly from the jugular veins of piglets at $d$ 28 of experiment (early morning, before pigs were fed) using a 22-gauge sterile needle and then transferred to a BD Vacutainer (Becton Dickinson, Franklin Lakes, NJ) without anticoagulant. All samples were quickly transferred into centrifuge tubes that were centrifuged for $15 \mathrm{~min}$ at $1,610 \times$ $\mathrm{g}$ in a cold chamber $\left(4^{\circ} \mathrm{C}\right)$. Sera were then carefully removed to plastic vials and stored at $-20^{\circ} \mathrm{C}$ until immunoglobulin analysis was performed. The concentrations of serum $\operatorname{IgG}, \operatorname{IgM}$, and $\operatorname{IgA}$ were assayed using Pig IgG (Cat. No. E100-104), IgM (Cat. No. E100100), and IgA (Cat. No. E100-102) ELISA Quantitation Kits (BETHYL Laboratories Inc., USA) according to the manufacturer's instructions. Each experiment was run in duplicate and the results represent means of three repeat experiments. The absorbance of each well was measured within $30 \mathrm{~min}$ by using microplate autoreader (Thermo Lab Systems, Finland) at $450 \mathrm{~nm}$. The results were expressed as $\mathrm{mg} / \mathrm{dL}$ of serum.

\section{Statistical analysis}

The pen was used as the experimental unit for the analysis of growth performance, whereas individual piglet was used as experimental unit for analysis of serum immunoglobulins and fecal microbiota. Results for all parameters under consideration were recorded for each experimental unit and, finally, subjected to ANOVA appropriate for a completely randomized design by using the general linear model procedures (GLM) of the SAS 
Institute Inc. (SAS, 2003). Statistically significant effects were further analyzed and means were compared using Duncan's multiple range tests. Probability values of $\mathrm{p}<0.05$ were considered as statistically significant, whereas $p<0.10$ was considered a tendency.

\section{RESULTS AND DISCUSSION}

\section{Growth performances}

There was no significant difference in initial body weight of piglets among the treatments (Table 2). Piglets fed PC diet had the highest ADG (35.2\%) and ADFI (27.2\%) compared to NC, T1 and T2 supplemented groups throughout the experimental period $(\mathrm{p}<0.05)$. Both PC $(10.4 \%)$ and T1 (13.5\%) supplemented groups showed improved gain:feed value during phase 1 and overall experimental period compared to NC and T2 supplemented group $(\mathrm{p}<0.05)$.

The positive effects of antibiotic growth promoters to combat the post-weaning growth lag experienced by pigs have been well established by many scientific studies (Cromwell, 1991; Doyle, 2001). The growth performance data indicated that, the apramycin-treated group performed remarkably better than the negative control and acidifiertreated groups, which is supported by the earlier work (Walsh et al., 2007a; Li et al., 2008). The growth promotional effects of these compounds may be the result of direct suppression of gastrointestinal microbes such as pathogenic E. coli, through nutrient sparing and by inhibition of gut urease activity and ammonia production (Yen and Pond, 1987). Significant reduction of ADFI in the citric acid supplemented group was supported by the previous studies of Falkowski and Aherne (1984) and Giesting and Easter (1985). The negative effect of citric acid on feed intake was also in agreement with Risley et al. (1993) who reported a reduction in ADFI in weaned piglets challenged with $E$. coli. On the other hand, the gain:feed was $13.5 \%$ higher in citric acid-treated group compared to negative control group, which is consistent with the findings of Tsiloyiannis et al. (2001) and Radecki et al. (1988). Kil et al. (2011) also reviewed that citric acid generally increased ADG and gain:feed but decreased ADFI. It is possible that the decreased feed consumption without affecting weight gain was a response to improved gain:feed of the animals. Dietary citric acid may lower the $\mathrm{pH}$ level of GIT which increases activity of proteolytic enzymes and gastric retention time, resulting in improved protein and amino acid metabolism and as thus improves feed efficiency (Partanen and Mroz, 1999). The acidifier blend used in this study, had a negative effect on the ADG, ADFI and gain:feed of weaned piglets throughout the experimental period. These results are in partial agreement with Walsh et al. (2007b) who reported a reduction of ADG, ADFI and gain:feed when $0.2 \%$ Kem-Gest (blend of phosphoric, fumaric, lactic, and citric acid) was added to a corn-soybean meal diet. Similarly, Walsh et al. (2004) reported reduced feed intake when dietary acidifiers (organic and inorganic acid-based blends) were included at $0.6 \%$ in weanling pig diets. On the contrary, Scheonherr (1994) reported increased growth performance of weanling pigs supplemented with a phosphoric acid-based acidifier containing other organic acids in a blend (citric, lactic and

Table 2. Effects of citric acid and acidifier blend on growth performance of weaned piglets ${ }^{1}$

\begin{tabular}{|c|c|c|c|c|c|c|}
\hline \multirow{2}{*}{ Parameters } & \multicolumn{4}{|c|}{ Treatment $^{2}$} & \multirow{2}{*}{$\mathrm{SE}^{3}$} & \multirow{2}{*}{ p-value } \\
\hline & $\mathrm{NC}$ & $\mathrm{PC}$ & $\mathrm{T} 1$ & $\mathrm{~T} 2$ & & \\
\hline Initial BW (kg) & 8.01 & 8.28 & 8.05 & 7.97 & 0.21 & 0.20 \\
\hline Final BW (kg) & 14.82 & 18.78 & 15.25 & 13.40 & 0.57 & $<0.01$ \\
\hline \multicolumn{7}{|l|}{ ADG (g) } \\
\hline d 0 to $\mathrm{d} 14$ & $300^{\mathrm{b}}$ & $379^{\mathrm{a}}$ & $329^{\mathrm{ab}}$ & $230^{\mathrm{b}}$ & 32.8 & $<0.01$ \\
\hline d 14 to $\mathrm{d} 28$ & $186^{\mathrm{b}}$ & $371^{\mathrm{a}}$ & $185^{\mathrm{b}}$ & $158^{\mathrm{b}}$ & 40.1 & $<0.01$ \\
\hline d 0 to $\mathrm{d} 28$ & $243^{\mathrm{b}}$ & $375^{\mathrm{a}}$ & $257^{\mathrm{b}}$ & $194^{\mathrm{c}}$ & 18.6 & $<0.01$ \\
\hline \multicolumn{7}{|l|}{ ADFI (g) } \\
\hline Phase $1(\mathrm{~d} 0$ to $\mathrm{d} 14)$ & $473^{\mathrm{ab}}$ & $496^{\mathrm{a}}$ & $445^{\mathrm{bc}}$ & $426^{\mathrm{c}}$ & 24.2 & $<0.01$ \\
\hline Phase 2 (d 14 to $\mathrm{d} 28)$ & $505^{\mathrm{b}}$ & $846^{\mathrm{a}}$ & $449^{\mathrm{c}}$ & $415^{\mathrm{c}}$ & 25.0 & $<0.01$ \\
\hline Overall ( 0 to $\mathrm{d} 28)$ & $489^{\mathrm{b}}$ & $671^{\mathrm{a}}$ & $447^{\mathrm{c}}$ & $421^{\mathrm{c}}$ & 21.2 & $<0.01$ \\
\hline \multicolumn{7}{|l|}{ Gain:feed } \\
\hline Phase $1(\mathrm{~d} 0$ to $\mathrm{d} 14)$ & $0.64^{\mathrm{bc}}$ & $0.77^{\mathrm{a}}$ & $0.74^{\mathrm{ab}}$ & $0.54^{\mathrm{c}}$ & 0.07 & $<0.01$ \\
\hline Phase 2 (d 14 to $\mathrm{d} 28)$ & 0.37 & 0.44 & 0.42 & 0.38 & 0.06 & 0.46 \\
\hline Overall ( 0 to $\mathrm{d} 28)$ & $0.50^{\mathrm{b}}$ & $0.56^{\mathrm{a}}$ & $0.58^{\mathrm{a}}$ & $0.46^{\mathrm{b}}$ & 0.03 & $<0.01$ \\
\hline
\end{tabular}

\footnotetext{
$\overline{\mathrm{a}, \mathrm{b}, \mathrm{c}}$ Means in a row with no common superscripts significantly differ $(\mathrm{p}<0.05)$.

${ }^{1}$ Values represent the means of three pens with five pigs per pen.

${ }^{2} \mathrm{NC}($ Negative control $)=$ Basal diet, PC (Positive control $)=$ Basal diet $+0.002 \%$ apramycin, $\mathrm{T} 1=\mathrm{Basal}$ diet $+0.5 \%$ citric acid, $\mathrm{T} 2=\mathrm{Basal}$ diet $+0.4 \%$ acidifier blend.

${ }^{3} \mathrm{SE}=$ Pooled standard error.
} 
fumaric acid). Generally, some organic acids (formic and propionic acid) have aggressive odors which may reduce diet palatability, thus decreasing feed intake and negatively impact the growth rate (Giesting and Easter, 1985; Kil et al., 2006; Walsh et al., 2007a). Furthermore, inorganic acids can reduce the palatability of feed and destroy the electrolyte balance, resulting in severe depression of growth (Easter, 1993). Therefore, inclusion of a mixture of organic and inorganic acids in the acidifier blend possibly decreases diet palatability and as thus reduces the growth performance of piglets.

\section{Fecal microflora population}

Microbial shedding was determined from fecal samples taken at regular intervals. There was no significant difference in fecal Salmonella count on d 7 among the treatment groups ( $p>0.05$; Figure 1). The PC diet had the highest inhibitory effect on fecal Salmonella count from d 14 onward, whereas $\mathrm{T} 1$ and $\mathrm{T} 2$ diets had intermediate effects compared to NC diet ( $<<0.05)$. In the case of fecal $E$. coli, no significant differences were found at $\mathrm{d} 7$ and $\mathrm{d} 14$ counts $(p>0.05)$. The results of $d 21$ and $d 28$ counts showed that all dietary treatments reduced fecal $E$. coli count compared to NC diet $(\mathrm{p}<0.05)$. Fecal Lactobacillus spp. count was not significantly differ on $\mathrm{d} 7$ among the
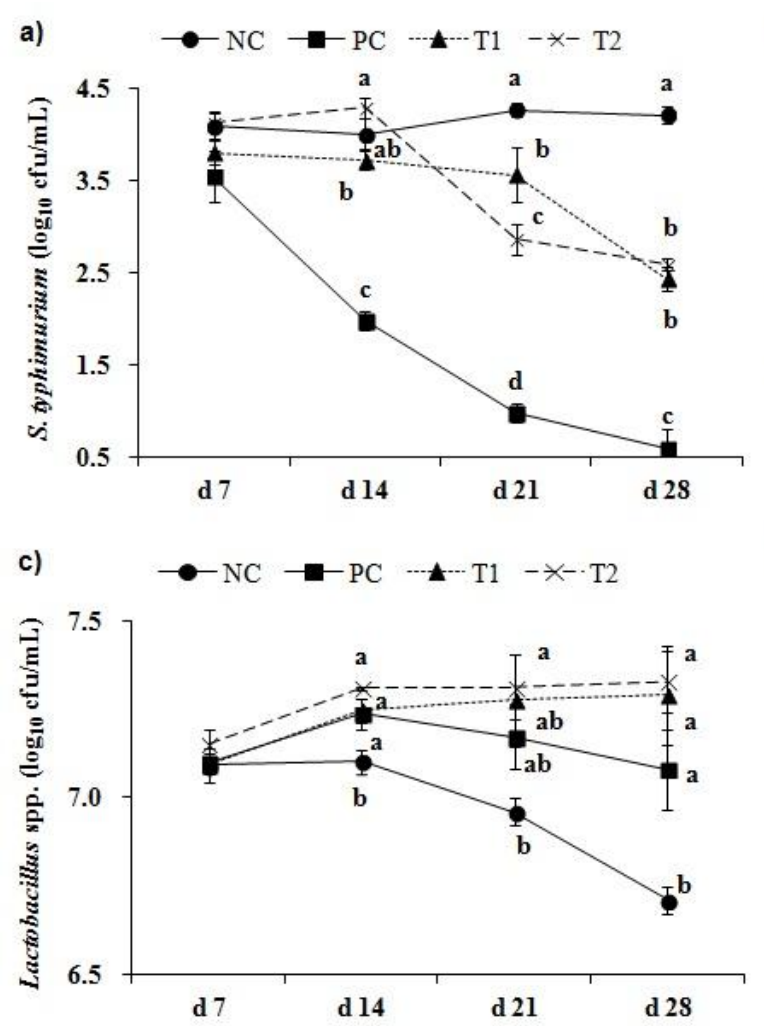

treatment groups $(\mathrm{p}>0.05)$. From d 14 onward, PC, T1 and $\mathrm{T} 2$ diets increased Lactobacillus spp. counts compared to NC diet $(\mathrm{p}<0.05)$. Fecal Bacillus count was also increased by $\mathrm{T} 1$ and $\mathrm{T} 2$ diets on $\mathrm{d} 21$ and $\mathrm{d} 28$ compared to $\mathrm{NC}$ and PC diets, respectively $(\mathrm{p}<0.05)$.

Previous studies have shown that, the number and species of intestinal microflora changed dramatically in piglets during the first few days after weaning (Barrow et al., 1977; Deng et al., 2007a; Wang et al., 2011). In the current study, dietary antibiotics and acidifiers significantly reduced fecal counts of pathogenic gram-negative Salmonella and E. coli and increased beneficial Lactobacilli and Bacilli concentrations compared to negative control. Our results are in agreement with Li et al. (2008) who found reduced $E$. coli and increased Lactobacilli concentration in antibiotic and organic acid treated weaned piglets. In contrary, Collier et al. (2003) reported that, feeding nursery pigs with antibiotic for 5 weeks suppressed the growth of small intestinal microbiota and reduced the total bacteria population. The favorable intestinal microbial modulation after feeding antibiotics can be attributed to the enhanced growth performance of pigs after oral challenge. It had been expected that dietary acidifiers would lower the intestinal $\mathrm{pH}$ and produce a more favorable environment for Lactobacilli (Fuller, 1989). The low pH and high counts of

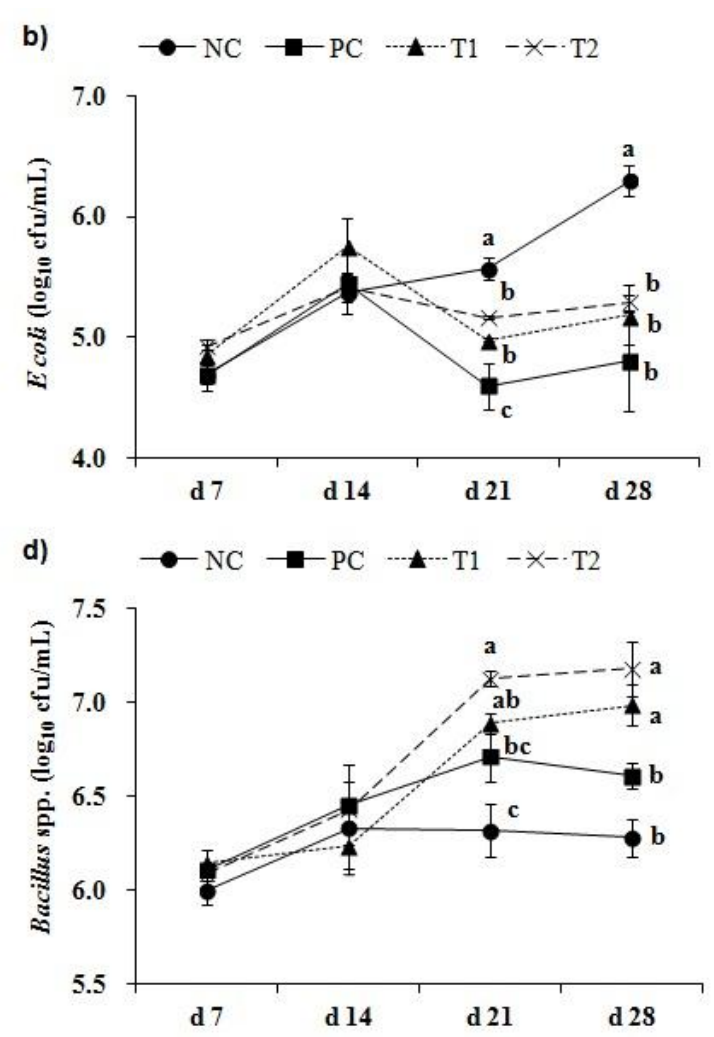

Figure 1. Effects of citric acid and acidifier blend on the fecal microflora population of weaned piglets. Values represent the means of three pens with two pigs per pen. NC: Negative control; basal diet, PC: Positive control; basal diet+0.002\% apramycin, T1: basal diet $+0.5 \%$ citric acid, T2: basal diet $+0.4 \%$ blend acidifier. Lines within a time period not sharing a common letter are significantly different $(\mathrm{p}<0.05)$. 
Table 3. Effects of citric acid and acidifier blend on humoral immune response of weaned piglets ${ }^{1}$

\begin{tabular}{|c|c|c|c|c|c|c|}
\hline \multirow{2}{*}{ Parameters } & \multicolumn{4}{|c|}{ Treatments $^{2}$} & \multirow{2}{*}{$\mathrm{SE}^{3}$} & \multirow{2}{*}{ p-value } \\
\hline & $\mathrm{NC}$ & $\mathrm{PC}$ & T1 & $\mathrm{T} 2$ & & \\
\hline $\mathrm{IgG}(\mathrm{mg} / \mathrm{dL})$ & $409^{\mathrm{ab}}$ & $366^{\mathrm{b}}$ & $473^{\mathrm{a}}$ & $418^{\mathrm{ab}}$ & 35.4 & 0.09 \\
\hline $\operatorname{IgM}(\mathrm{mg} / \mathrm{dL})$ & 30.2 & 29.9 & 30.2 & 30.0 & 0.74 & 0.95 \\
\hline $\operatorname{IgA}(\mathrm{mg} / \mathrm{dL})$ & 6.33 & 5.80 & 6.60 & 6.50 & 0.85 & 0.68 \\
\hline
\end{tabular}

Lactobacilli may inhibit the colonization and proliferation of E. coli and Salmonella by blocking possible intestinal receptors and by secreting metabolites acting against acidintolerance bacteria (Roth and Kirchgessner, 1998; Dibner and Buttin, 2002). It is also possible that organic acid provides extra energy for aerobic beneficial bacterial growth (Chaveerach et al., 2004). Walsh et al. (2003) observed that addition of organic acids promotes reduction of fecal E. coli and elevation of Lactobacillus, consistent with the findings of Cole et al. (1968). This result was further supported by Thomlinson and Lawrence (1981), who observed reduction of both E. coli multiplication and piglet mortality as a result of acidification. These studies collectively confirmed the favorable modulatory effects of acidifiers on the indigenous gut microbial population and the similarity of citric acid and acidifier blend with antibiotics in regard to antimicrobial activity.

\section{Humoral immunity}

The effects of antibiotic and acidified feeds on the serum immunoglobulins ( $\operatorname{IgG}, \operatorname{IgM}$, and $\operatorname{IgA}$ ) of weaned piglets are shown in Table 3. Supplementation of citric acid diet increased serum IgG, IgM, and IgA levels, although only IgG was significantly affected $(\mathrm{p}<0.05)$. The PC diet showed the poorest immune response among all treatments $(\mathrm{p}<0.05)$.

The concentration of immunoglobulin in the extracellular fluid can be used as an indicator to measure the humoral immune response (Deng et al., 2007a; Yin et al., 2008). Indeed, serum IgG, IgA and IgM are the major serum immunoglobins that protect the extravascular compartment against pathogenic viruses and microorganisms (Deng et al., 2007a; Li et al., 2007). Gomez et al. (1998) reported that serum IgG protects the intestinal gut surface from bacterial damage, thereby maintain optimal intestinal function and gastrointestinal growth, which in turn is beneficial for health and growth performance of piglets. Maturation and optimal development of the immune system after birth are dependent on the development and composition of the indigenous microflora and vice versa (De Vrese and Marteau, 2007). Although the effects of organic acids on the immune response have not been well documented yet, it is clear that many types of organic acids (including citric acid) can alter the intestinal gut microflora, which is necessary for the development of the immune system (Blum et al., 2002; Guo et al., 2008). Citric and other organic acid stimulates specific and non-specific immune functions by modulating the composition of intestinal microbiota against harmful organisms (Van der Wielen et al., 2000), as well as lowering the intestinal $\mathrm{pH}$ in order to decrease disease sensitivity. In addition, organic acidifiers are known to reduce the incidence of subclinical infections as well as modify the immune system (Dibner and Buttin, 2002). However, no comparisons with other studies could be made here since there were no other studies on the effects of citric acid on immunoglobulins in pigs. The poor immune response of the antibiotic-treated group could be attributed to the immunosuppressive effect of apramycin, an aminoglycoside antibiotic. Roura et al. (1992) reported that antibiotics may function by preventing immune activation and decreasing the magnitude of immune response after enteric challenge.

\section{CONCLUSION}

Taken together, dietary supplementation of apramycin had significantly improved the growth performance and reduced pathogenic microbial load of piglets under challenged conditions. Acidification of the diet with citric acid positively affects the feed conversion ratio and reduced pathogenic bacterial load which was comparable with apramycin. Dietary supplementation of citric acid increased beneficial bacterial counts and serum $\operatorname{IgG}$ concentration compared to control and apramycin supplemented group. Supplementation of the acidifier blend used in this study had a negative impact on growth performance parameters, but it positively influenced the intestinal microflora population, suggesting further investigation with different inclusion levels.

\section{ACKNOWLEDGEMENT}

The authors gratefully acknowledge the financial support provided by the Cooperative Research Program for 
Agriculture Science \& Technology Development, Rural Development Administration (Project No. PJ007605062011) and National Research Foundation of Korea (Project No. 07-009), Republic of Korea.

\section{REFERENCES}

AACC. 2000. Approved Methods of the American Association of Cereal Chemists. 10th ed. Method 02-52. The Association, St. Paul, MN, USA.

Barnett, K. L., E. T. Kornegay, C. R. Risley, M. D. Lindemann, and G. G. Schurig. 1989. Characterization of creep feed composition and its subsequent effects on immune response, scouring index and performance of weanling pigs. J. Anim. Sci. 67:2698-2708.

Barrow, P. A., R. Fuller, and M. J. Newport. 1977. Changes in the microflora and physiology of the anterior intestinal tract of pigs weaned at 2 days, with special reference to the pathogenesis of diarrhea. Infect. Immun. 18:586-595.

Bauer, E., B. A. Williams, C. Voigt, R. Mosenthin, and M. W. A. Verstegen. 2001. Microbial activities of faeces from unweaned and adult pigs, in relation to selected fermentable carbohydrates. Anim. Sci. 73:313-322.

Blum, S., D. Haller, A. Pfeifer, and E. J. Schiffrin. 2002. Probiotics and immune responses. Clin. Rev. Allergy Immunol. 22:287309.

Chaveerach, P., D. A. Keuzenkamp, L. J. Lipman, and F. Van Knapen. 2004. Effect of organic acids in drinking water for young broilers on Campylobacter infection, volatile fatty acid production, gut microflora and histological cell changes. Poult. Sci. 83:330-334

Chopra, S. L., A. C. Blackwood, and D. G. Dale. 1964. Enteritis of early weaned pigs: 1 . Enteropathogenic Escherichia coli. Can. J. Comp. Med. Vet. Sci. 28:239-242,243-247.

Cole, D. J., R. M. Beal, and J. R. Luscombe. 1968. The effect on performance and bacterial flora of lactic acid, propionic acid, calcium propionate and calcium acrylate in the drinking water of weaned pigs. Vet. Rec. 83:459-464.

Collier, C. T., M. R. Smiricky-Tjardes, D. M. Albin, J. E. Wubben, V. M. Gabert, B. Deplancke, D. Bane, D. B. Anderson, and H. R. Gaskins. 2003. Molecular ecological analysis of porcine ileal microbiota responses to antimicrobial growth promoters. J. Anim. Sci. 81:3035-3045.

Cromwell, G. L. 1991. Antimicrobial agents. In: Swine Nutrition (Ed. E. R. Miller, D. E. Ullrey, and A. J. Lewis). ButterworthHeiemann, Stoneham, MA, USA. pp. 297-314.

De Vrese, M. and P. R. Marteau. 2007. Probiotics and prebiotics: Effects on diarrhea. J. Nutr. 137:803S-811S.

Deng, Z. Y., J. W. Zhang, G. Y. Wu, Y. Yin, Z. Ruan, T. J. Li, W. Y. Chu, X. F. Kong, Y. M. Zhang, Y. W. Fan, R. Liu, and R. L. Huang. 2007b. Dietary supplementation with polysaccharides from Semen cassiae enhances immunoglobulin production and interleukin gene expression in early-weaned piglets. J. Sci. Food Agric. 87:1868-1873.

Deng, Z. Y., J. W. Zhang, J. Li, Y. W. Fan, S. W. Cao, R. L. Huang, Y. L. Yin, H. Y. Zhang, and T. J. Li. 2007a. Effect of polysaccharides of cassiae seeds on the intestinal microflora of piglets. Asia Pac. J. Clin. Nutr.16 (Suppl 1):143-147.
Dibner, J. J. and P. Buttin. 2002. Use of organic acid as a model to study the impact of gut microflora on nutrition and metabolism. J. Appl. Poult. Res. 11:453-463.

Doyle, M. E. 2001. Alternatives to antibiotic use for growth promotion in animal husbandry. FRI briefings, Food Research Institute, University of Wisconsin-Madison, WI. pp. 1-17.

Easter, R. A. 1993. Acidification of diets for pigs. In: Recent Developments in Pig Nutrition 2 (Ed. D. J. A. Cole, W. Haresign, and P. C. Garnsworthy). Nottingham University Press, Nottingham. pp. 256-266.

Eidelsburger, U. 1998. Feeding short-chain organic acids to pigs. In: Recent Advances in Animal Nutrition (Ed. P. C. Garnsworthy and J. Wiseman) Nottingham University Press, Nottingham. pp. 93-106.

Falkowski, J. F. and F. X. Aherne. 1984. Fumaric and citric acid as feed additives in starter pig nutrition. J. Anim. Sci. 58:935-938.

Fuller, R. 1989. Probiotics in man and animals. J. Appl. Bacteriol. 66:365-378.

Fuller, R. 1992. History and development of probiotics. In: Probiotics (Ed. R. Fuller). pp. 1-8. Chapman and Hall, London.

Gabert, V. M. and W. C. Sauer. 1994. The effects of supplementing diets for weanling pigs with organic acids. A review. J. Anim. Feed Sci. 3:73-87.

Giesting, D. W. and R. A. Easter. 1985. Response of starter pigs to supplementation of corn-soybean meal diets with organic acids. J. Anim. Sci. 60:1288-1294

Gomez, G. G., O. Philips, and R. A. Goforth. 1998. Effect of immunoglobulin source on survival, growth and hematological and immunological variables in pigs. J. Anim. Sci. 76:1-7.

Guo, G., Y. Liu, W. Fan, J. Han, Y. Hou, Y. Yin, H. Zhu, B. Ding, J. Shi, J. Lu, H. Wang, J. Chao, and Y. Qu. 2008. Effects of Achyranthes Bidentata polysaccharide on growth performance, immunological, adrenal, and somatotropic responses of weaned pigs challenged with Escherichia coli lipopolysaccharide. Asian-Aust. J. Anim. Sci. 21:1189-1195.

Hansen, C. F., A. L. Riis, S. Bresson, O. Højbjerg, and B. B. Jensen. 2007. Feeding organic acids enhances the barrier function against pathogenic bacteria of the piglet stomach. Livest. Sci. 108:206-209.

Kil, D. Y., W. B. Kwon, and B. G. Kim. 2011. Dietary acidifiers in weanling pig diets: a review. Rev. Colomb. Cienc. Pecu. 24:231-247.

Kil, D. Y., L. G. Piao, H. F. Long, J. S. Lim, M. S. Yun, C. S. Kong, W. S. Ju, H. B. Lee, and Y. Y. Kim. 2006. Effect of organic or inorganic acid supplementation on growth performance, nutrient digestibility and white blood cell counts in weanling pigs. Asian-Aust. J. Anim. Sci. 19:252-261.

Korean Ministry for Food, Agriculture, Forestry and Fisheries. 2008. Guidelines for the care and use of animals in research. Korean Ministry for Food, Agriculture, Forestry and Fisheries, Seoul, Korea.

Kyriakis, S. C. 1989. New aspects of the prevention and/or treatment of the major stress induced diseases of the early weaned piglet. Pig News Inf. 2:177-181.

Li, P., Y. L. Yin, D. Li, S. W. Kim, and G. Wu. 2007. Amino acids and immune function. Br. J. Nutr. 98:237-252.

Li, Z., G. Yi, J. Yin, P. Sun, D. Li, and C. Knight. 2008. Effects of organic acids on growth performance, gastrointestinal $\mathrm{pH}$, intestinal microbial populations and immune responses of 
weaned pigs. Asian-Aust. J. Anim. Sci. 21:252-261.

Marinho, M. C., M. M. Lordelo, L. F. Cunha, and J. P. B. Freire. 2007. Microbial activity in the gut of piglets: I. Effect of prebiotic and probiotic supplementation. Livest. Sci. 108:236239.

Mathew, A. G., A. L. Sutton, A. B. Scheidt, D. M. Forsyth, J. A. Patterson, and D. T. Kelly. 1991. Effects of a propionic acid containing feed additive on performance and intestinal microbial fermentation of the weanling pigs. In: Proceedings of the 6th International Symposium on the Digestive Physiology in Pigs. PUDOC. Wageningen, The Netherlands. pp. 464-469.

NRC. 1998. Nutrient requirements of swine. 10th edn. National Academy Press, Washington, DC, USA.

Partanen, K. H. and Z. Mroz. 1999. Organic acids for performance enhancement in pig diets. Nutr. Res. Rev. 12:117-145.

Radecki, S. V., M. R. Juhl, and E. R. Miller. 1988. Fumaric and citric acids as feed additives in starter pig diets: effect on performance and nutrient balance. J. Anim. Sci. 66:2598-2605.

Radcliffe, J. S., Z. Zhang, and E. T. Kornegay. 1998. The effects of microbial phytase, citric acid, and their interaction in a cornsoybean meal-based diet for weanling pigs. J. Anim. Sci. 76:1880-1186.

Risley, C. R., E. T. Kornegay, M. D. Lindemann, C. M. Wood, and W. N. Eigel. 1993. Effect of feeding organic acids on gastrointestinal digesta measurements at various times postweaning in pigs challenged with enterotoxigenic Escherichia coli. Can. J. Anim. Sci. 73:931-940.

Roth, F. X. and M. Kirchgessner. 1998. Organic acids as feed additives for young pigs: Nutritional and gastrointestinal effects. J. Anim. Feed Sci. 7:25-33.

Roura, E., J. Homedes, and K. C. Klasing. 1992. Prevention of immunologic stress contributes to the growth-permitting ability of dietary antibiotics in chicks. J. Nutr. 122:2283-2290.

SAS Institute Inc. 2003. SAS user's guide. 9.1 Edition, SAS Institute Inc., Cary, North Carolina, USA.

Schoenherr, W. D. 1994. Phosphoric acid-based acidifiers explored for starter diets. Feedstuffs 66 (40, Sept. 26, 1994). pp. 14-15.

Sciopioni, R., G. Zaghini, and B. Biavati. 1978. Researches on the use of acidified diets for early weaning of piglets. Zootechnol. Nutr. Anim. 4:201-218.

Smith, H. W. and J. E. T. Jones. 1963. Observations on the alimentary tract and its bacterial flora in healthy and diseased pigs. J. Pathol. Bacteriol. 86:387-412.

Thomlinson, J. R. and T. L. Lawrence. 1981. Dietary manipulation of gastric $\mathrm{pH}$ in the prophylaxis of enteric disease in weaned pigs: Some field observations. Vet. Rec. 109:120-122.
Tsiloyiannis, V. K., S. C. Kyriakis, J. Vlemmas, and K. Sarris. 2001. The effect of organic acids on the control of porcine post-weaning diarrhoea. Res. Vet. Sci. 70:287-293.

Van der Wielen, P. W. J. J., S. Biesterveld, S. Notermans, H. Hofstra, B. A. P. Urlings, and F. Van knapen. 2000. Role of volatile fatty acids in development of the cecal microflora in broiler chickens during growth. Appl. Environ. Microbiol. 66:2536-2540.

Walsh, M. C., B. T. Richert, A. L. Sutton, J. S. Radcliffe, and R. Odgaard. 2004. Past, present, and future uses of organic and inorganic acids in nursery pig diets. In: Proceedings of the American Association of Swine Veterinarians, Des Moines, IA. pp. 155-158.

Walsh, M. C., D. M. Sholly, R. B. Hinson, K. L. Saddoris, A. L. Sutton, J. S. Radcliffe, R. Odgaard, J. Murphy, and B. T. Richert. 2007a. Effects of water and diet acidification with and without antibiotics on weanling pig growth and microbial shedding. J. Anim. Sci. 85:1799-1808.

Walsh, M. C., D. M. Sholly, R. B. Hinson, S. A. Trapp, A. L. Sutton, J. S. Radcliffe, J. W. Smith II, and B. T. Richert. 2007b. Effects of Acid LAC and Kem-Gest acid blends on growth performance and microbial shedding in weanling pigs. J. Anim. Sci. 85:459-467.

Walsh, M., D. M. Sholly, D. Kelly, M. Cobb, S. Trapp, R. Hinson, B. Hill, A. Sutton, S. Radcliffe, B. Harmon, J. Smith, and B. Richert. 2003. The effects of supplementing weanling pig diets with organic and inorganic acids on growth performance and microbial shedding. Purdue University 2003 Swine Research Report. pp. 89-98.

Wang, S., F. Blachier, F. Zhao, and Y. Yin. 2011. Intestinal microbiota: Development, metabolism and functions. J. Food Agric. Environ. 9:121-129.

Wu, X., Y. Zhang, Z. Liu, T. J. Li, and Y. L. Yin. 2012. Effects of oral supplementation with glutamate or combination of glutamate and $\mathrm{N}$-carbamylglutamate on intestinal mucosa morphology and epithelium cell proliferation in weanling piglets. J. Anim. Sci. 90:337-339.

Yen, J. T. and W. G. Pond. 1987. Effect of dietary supplementation with vitamin $\mathrm{C}$ or carbadox on weanling pigs subjected to crowding stress. J. Anim. Sci. 64:1672-1681.

Yin, Y. L., Z. R. Tang, Z. H. Sun, Z. Q. Liu, T. J. Li, R. L. Huang, Z. Ruan, Z. Y. Deng, B. Gao, L. X. Chen, G. Y. Wu, and S. W. Kim. 2008. Effect of galacto-mannan-oligosaccharides or chitosan supplementation on cytoimmunity and humoral immunity response in early-weaned piglets. Asian-Aust. J. Anim. Sci. 21:723-731. 